\title{
The Role of Knowledge Management and Internal Communication for a Better Quality Assurance in Higher Education Institution
}

\author{
Suzana Košir \\ International School for Social and Business Studies, Slovenia
}

\begin{abstract}
A successful higher education institution (hereinafter HEI) has to carefully plan, manage and verify its performance by outlining a strategy to achieve performance outcomes. The main focus lies on effectively managing knowledge within an HEI along with establishing quality assurance structures and mechanisms that measure and assess the organizations' performance and a successful internal communication as a tool to achieve quality assurance. In higher education institutions quality often reflects from the quality of educational process, quality management and its participation with the environment. Our paper deals with setting parallels between knowledge management processes and quality assurance processes and the importance of efficient internal communication. Therefore we reviewed the literature with critical appraisal and compilation method and created a model of comparison and intersection between knowledge management processes and quality assurance processes in higher education institutions thru internal communication. We can conclude that efficient and effective KM and internal communication cannot be achieved without extensive behavioral, cultural and organizational change that includes at least some aspects of quality assurance.
\end{abstract}

\section{Introduction}

There are many organizations that they have serious difficulties understanding the knowledge resource and they still lack an effective theoretical framework for understanding the operations of the organizations in the knowledge based society.

Most organizations tend to enhance recognition, creation and accumulation of new knowledge, derived from good practice and knowledge within the organization itself. With such action the organization has much leverage to efficiently interact with the environment. Moreover the obtained data can be easily converted into knowledge, based on a combination of experiences and values of the organization. Knowledge Management (hereinafter referred to as $\mathrm{KM}$ ) plays a crucial role in this process because it comprises the whole knowledge of and in the organization [22]. It has the virtue of a holistic approach and is responsible for acquiring and preserving knowledge, as well as for the creation, development and exploitation of new knowledge in the organization.

Bergeron provides a view that $\mathrm{KM}$ is a deliberate and systematic business strategy that selects, organizes, sets and distributes information that is relevant to the organization [3]. On the other hand Liebowitz argues that KM is the process of creating value from intangible assets within the organization [11]. $\mathrm{KM}$ is a collective working practice, which is focused on improving human resources and skills of the employees. Similar Collison and Parcell define $\mathrm{KM}$ as a point of intersection between functional areas of learning and organizational development, human resources and information technology [4].

Different types of knowledge need different management approach. Therefore it is important to understand the nature of various types of knowledge [2]. Our focus will primarily be on implicit and explicit knowledge and less on other types of knowledge like formal and informal knowledge, declarative and procedural knowledge, general and specific knowledge, etc.

Implicit knowledge is also referred to as tacit knowledge and is difficult to express and formalize and therefore difficult to share [2]. This knowledge affects the employees and the organization in terms of ability, innovation and continuous adaptation to new developments. Implicit knowledge includes insights, experience, intuition, hunches and everything that is hidden deep within every employee, which is why it is hard to transmit to others. Explicit knowledge refers to "written knowledge" that can be expressed with words and numbers and is therefore defined, stored and transferable. It is located in the texts, diagrams, tables, manuals, drawings, audio and video tapes, patents, computer programs etc. Because of this it is easy accessible, can be better understood and transferred in different forms.

Managing the knowledge in a successful manner implies that an organization should apply KM processes, following five phases: knowledge identification or capture, knowledge creation, knowledge transfer or sharing, knowledge application or use and knowledge storage. 
At the same time we have to be focus also on internal communication as a tool to conduct all phases of KM and quality assurance.

Our aim of the paper is to review KM processes within the Higher Education Institutions (hereinafter referred to as HEIs) and relate them to quality assurance through internal communication. Therefore we reviewed the literature with critical appraisal and compilation method to create a model of comparison and intersection between KM processes and quality assurance processes in HEIs.

\section{The Role of KM in HEIs}

Knowledge Management is a part of the overall management. It focuses on the systematic analysis, planning, acquiring, creating, developing, storing, and using of knowledge within the organization. It is also trying to transform the human capital into structural capital of the organization. Knowledge management is becoming increasingly important a central activity in the modern organization. The main function of knowledge management is the planning, implementation, management and control of all activities related to knowledge. $\mathrm{KM}$ is an activity that allows the company to make the best use of funds and resources that the company has available. It can be defined as an occupation that involves the detection, identification, transfer and use of knowledge. It is important to strengthen the influence of skills in a cost-effective way to achieve the company's goals.

Today, the creation of knowledge is also necessary after the completion of formal education and when an individual enters the working process. Knowledge, skills and practical skills acquired outside the school, in non-formal and informal settings are becoming more and more important. The knowledge has its maximum value if it's modern, relevant and accessible.

Wang defines the creation of knowledge as a process of acquisition and absorption of knowledge [21]. He is aware that all knowledge is not always in accordance with the requirements of the organization. Each organization must acquire those skills that are tailored to their needs, but it can also be usefully applied.

The emergence of knowledge economy has related KM even closely to the HEIs. Koren argues that management in education is like a bridge between the optimal implementation of the curriculum, priority setting, integrating employees in education, working with people, engaging with stakeholders in the environment, achieving the vision and goals of educational institutions and also identifying weaknesses and strengths [9]. The process of management in education contains more features. For example a major impact on the implementation of certain features has the state with its legislation, because it establishes the framework of competences and performance management. Another example is instructional leadership as it also contains all the features of KM process.

Top management in HEIs consists of representatives of Higher education leadership (dean, director, vice director), who are responsible for the organization's policy, internal communication and providing quality service. They also have to provide a level of quality, appearance and the means of achieving the planned objectives by monitoring in order to ensure adequate and appropriate resources where KM plays an important role in the realization of these tasks.

\section{KM Processes}

Effective management within the organization is considered when it relies on KM processes and quality assurance processes in place. First we will deal with managing the processes of knowledge within HEIs and then we will move on to internal communication and quality. KM identified five phases: knowledge identification/capture, knowledge creation, knowledge transfer/sharing, knowledge application/use and knowledge storage. On the other hand KM processes can also be expressed by four components: planning, organizing, leading and controlling the knowledge, experience, abilities and skills [7].

Below, we define five phases of $\mathrm{MZ}$ processes in detail.

\subsection{Knowledge Identification/Capture}

Knowledge identification, recognition or capture may be defined as the development or the process of retrieving implicit or explicit knowledge of employees. Creation of knowledge, which is the second phase, is then imposed if the leadership is encouraging and motivating creative employees. New knowledge can be gained from obtained data and information or it can be deducted from existing knowledge [6].

On the one hand, the task of the organizations' management is to establish and maintain processes of $\mathrm{KM}$ and on the other hand, the task of all employees in the organization is to create new knowledge [5]. Nonaka and Takeuchi argue that knowledge is created by the interaction between explicit and implicit work [16]. The authors note that constant generation of new knowledge, dissemination and successful integration into the work processes leads to a successful company. The biggest value for the company is when the knowledge is used by as many employees as possible [10].

In the initial phase it is necessary to determine which employees have the knowledge, not only discovering skills that an individual uses at work, but 
also all the skills that he possess. This is often for the detection of tacit knowledge, which was not aware that an individual possesses and usually it remains unused.

\subsection{Knowledge Creation}

The way of creating new knowledge depends on the interests, needs, costs and opportunities, undertaken by the organization One of the most important tasks of $\mathrm{KM}$ is to protect knowledge and at the same time managing the creation of new knowledge, as it would otherwise be faced with the problem of obsolescence. The most common way to gain new knowledge is through education and training employees and also by allowing employees to be mobile in work. With employee training, knowledge, work experience and attitude are transferred to employees, which can provide a personal example of a relationship with colleagues. The training is able to replace the lack of knowledge, skills or competencies, but the main quality is to tailor the missing knowledge to the needs of employees. To determine the need for education and training, monitoring key tasks of employees or competences are used along with regular annual interviews to gain career path information and expertise of employees.

Learning and knowledge gaining is mostly attributable to the acquisition of formal education or participation in seminars or workshops, but it is also very important a cooperative learning where teachers and educators acquire knowledge from each other, share good practice and learn from each other.

In the process of knowledge creation it is very important encouraging and motivating employees. It is also very important the sense of freedom of action, which opens up possibilities for new and creative ideas.

Among the most important methods of acquiring knowledge from external sources belongs to an imitation of successful practices of other companies, for example:

- Participation at the conference.

- Reading a variety of sources (journals, newspapers, e-mail).

- Monitoring the economic, social, technological, political trends.

- Recruitment of a new staff.

- Collaboration with various organizations and institutions.

\subsection{Knowledge Transfer/Sharing}

Knowledge that members of society gain at various education and training, knowledge that they acquire by themselves, or with experience in other ways, the knowledge they receive in interaction with stakeholders must be effectively transferred and extended to other individuals, units and society as a whole.

Knowledge transfer is a process where implicit or explicit knowledge held by individuals, groups or organizations are disseminated, transferred or transmitted to other individuals, groups or organizations [2]. Most often is knowledge transferred from where knowledge is created to where this knowledge is most useful and desirable. Holders of knowledge are people, co-workers and employees of an organization. There are two types of knowledge transfer. First is intentional and second unintentional. Unintentional knowledge transfer includes an unscheduled action between employees, informal networks and bonding of employees outside the working hours.

Knowledge transfer between employees is influenced by organizational culture, managerial style, structure and systems of the organization itself, human and technical skills, values and resources. Well-developed communication and rules of communication within the organization contributes to faster knowledge exchange. If implicit knowledge does not transform into explicit knowledge, than there is a lack of communication between employees [5]. The stronger communication system is, leads to faster knowledge transmission. Systems for knowledge transfer enable employees of the organization to tolerate and comprise explicit and implicit knowledge of each other. Therefore we could also name it as knowledge market, enabling both the transmission and exchange of knowledge between employees [6].

Knowledge transfer is important to the proper conduct by an example to other, the trust between employees, employee motivation, adequate organizational culture, organizational and technological support and last but not least by careful recruitment.

A key role that plays in knowledge transfer is communication rules. Due to inadequate organizational culture that doesn't have positive attitude, problems may arise in the transfer of tacit knowledge.

The key forms of personal knowledge transfer in the organizations are:

- Mandatory reports.

- Regular meetings and records of the meetings.

- Internal trainers who are trained for the knowledge transfer.

- Various forms of internal libraries.

- Promoting and recording of self-education.

\subsection{Knowledge Application/Use}

Knowledge application is considered when a direct formation of added value takes place in the 
organization. But access to the knowledge does not necessarily mean knowledge application. Existing knowledge has to be used to create new knowledge, new added value, followed by the transfer and storage of knowledge. For effective application of knowledge, it is important to have different sources of knowledge and frequent contact among employees and also, from the perspective of the knowledge use, relevant information and communication technology, which enables wider access to knowledge and promotes the production of knowledge that employees need.

For effective use of knowledge it is right using different sources of knowledge and having frequent contacts with people. Because it is the only way to illuminate the same case from different angles and it can be solved in different ways. From these point of view teams and various working meetings, where people work together, are very important and in this way they mainly use their own implicit knowledge. For the use of explicit knowledge information technology is very important, which does not promote the use of knowledge, it enables knowledge in a far more quick and easy way when the employee needs. Information technology therefore represents the engine and the kind of support system to a knowledge management.

\subsection{Knowledge Storage}

Knowledge acquired by the organization has to be adequately stored, which is not an easy task, since the organization has to ensure that new knowledge is not lost. This can be achieved with well-developed communication and technology system, enabling better knowledge transfer between employees. When it comes to knowledge storage, it includes technical processes (database records, structured documents, reports, patents) and human processes (the memorizing on the individual and collective level). If the organization does not adequately store new and existing knowledge, it can have difficulty to regain obtained knowledge. Knowledge must be properly structured, divided into categories and organized in a way that is in due time accessible to all who need it.

In technical processes, where there is explicit knowledge usually do not have problems, because we can access them whenever we want. In human processes when it comes to implicit knowledge is a very important personal approach and dialogue as the only way we can reach this knowledge.

Unfortunately, a lot of knowledge is lost too. This comes mostly due to the lack of technology for sharing documents, weak support communication and isolation of different sources of information. The loss of knowledge also contributes outflow of employees - either due to retirement or the voluntary or involuntary employee turnover.

\section{Quality in HEIs}

The second very important aspect of HEIs is quality assessment. While management in education has the role of integration, strategic planning and realization of the vision and objectives of the HEIs, the quality is demonstrated through standards, philosophies and behavioral norms of individual HEIs that makes the difference between excellent and average HEIs. Quality in education can be understood as philosophy of the HEI that is constantly evolving in the direction of increasing the satisfaction of all parties involved in the educational process, which can be used as a measure of the quality of education.

Quality can be also understood as the sum of all properties and characteristics of a product, process or service [8]. Furthermore Ferjan states that quality implies compliance with the needs and expectations [8]. On the other hand Glasser argues that quality is everything we do, learn and whatever satisfies our needs [15]. When employees feel that quality is a value, then they will strive to it without adapting to externally established criteria. According to the European vision of quality, the quality is the relationship between requirements and actual results, the difference between what we expect and what we get. It helps us to distinguish right from wrong, acceptable from unacceptable, working inefficient from efficient. Quality is based on values and is reflected in the choice.

Quality assurance in higher education is not only a European problem. Worldwide growing interest in quality and standards, reflecting both the rapid growth of higher education as a cost and it brings it to the public and individuals. So if Europe wants to achieve its goal of becoming the most dynamic knowledge-based society in the world (Lisbon Strategy), the European higher education will have to show the quality of its programs and diplomas and to be prepared to establish ways of ensuring and demonstrating that quality. Initiatives and requirements at internationalization from inside and outside Europe require a response.

Between European standards and guidelines for internal quality assurance is also the provision of quality teaching staff. Institutions have ways to ensure that staff working with students is qualified for the job. Teachers are the most important source of learning. It is important that those who teach, extensive knowledge and understanding of the subject they teach the necessary skills and experience, they have to transfer their knowledge and understanding to students in a number of teaching contexts, and that are available to give them feedback on the performance of the work. Institutions should ensure that procedures for recruitment and appointment of their staff include a way of ensuring that all new staff has at least the 
minimum required level of competence. Teaching staff should be given the opportunity to develop and disseminate educational qualification and incentive for their skills. Institutions should the worst teachers help to improve their skills to an acceptable level.

Employees have to be aware that the quality does not just happen; it has to be constantly on their mind to implement it. Turnšek defines quality in HEIs as "ensuring best practice", which includes defining quality evaluation or quality assessment and changing practice, followed by re-evaluation [20].

The idea on improving the quality, ideas on improving interpersonal relations between people within higher education institutions and that way the quality of higher education institutions has to start as a reflection on their vision, values and mission. Quality in higher education can be improved through direct and meaningful use of successful approaches and models of economic sectors, which can be redesigned for higher education.

Processes of quality assurance are vital for the proper functioning of a higher education institution. The key elements are: strategy for quality assurance (consideration of standards with defined mission and vision), rules of procedure for quality (they show that an establishment follows and improves quality and efficiency of its function), incorporation of all participants in the quality assessment of functioning (periodical evaluations and self-evaluations), diverse reports (evaluations, self-evaluations, annual reports about functioning of the establishment, financial plans, work plans and advisory services, collecting and analyzing data from the entire organization). Quality assurance is an ongoing process, based on regular training and education of employees in an educational organization. A thorough evaluation offers a realistic picture, the basic aim of which is to identify the areas for improvement and put into place the necessary tools to carry through with the improvements. Evaluation in educational organizations is typically directed to decisionmaking, since the essence of evaluation is to improve educational politics and methods. Systematic assessment and quality assurance are the reasons that evaluation was introduced in educational organizations. Evaluation can help professional employees, since it improves their work and contributes to better quality as a consequence. Correctly performed evaluations reveal the true conditions, which is also another goal.

Achieving quality is based on continuous improvement and evaluating study programs and higher education institutions. A key role at that is in the development of a culture of quality. For the quality of higher education is primarily the responsibility of higher education institutions, in collaboration with all partners. Measuring the quality of higher education is with set of clear and measurable criteria. National criteria define the minimum criteria and procedures as are necessary to assess whether higher education institutions and study programs are eligible for accreditation.

\section{Internal Communication}

Internal communication is a key factor in bringing about change in the organization. Many authors define the internal communication as influence on the motivation of employees to support the organization and the achievement of its objectives. They emphasize the importance of good interpersonal relations, sense and goals of the individual, strengthening the sense of belonging to the company and cooperation between management and employees Smith and Mounter point out that in recent year's internal communication is shifted from the events and people in the organization to achievement of the objectives of the organization [10] [18].

To achieve the objectives of the organization we need to establish knowledge management processes for the effective quality assurance of higher education institution.

Mumel considered the system of internal communication as a tool for achieving flexibility, the ability of organization to adapt quickly of the current situation on the market [14].

The purpose of internal communication is socialization of employees, employees' identification with the company, training and information for staff, animating and persuading employees, to achieve motivation and loyalty among employees, to develop positive interpersonal relationships. Interpersonal relationships are very important for the development of the human personality in the social, emotional and intellectual sense. Based on a relationship with other human beings they create their own identity. Based on the response of others they can help them to develop the most clear and accurate picture of themselves. Effective and satisfying interpersonal relationships are a prerequisite for the personal and professional satisfaction of employees.

If we want to relate, maintain and develop good interpersonal relationships, we need to know the basic skills such as: (1) interpersonal understanding and trust - self-revelation, self-awareness and acceptance of oneself; (2) communication - refers to the precise and unambiguous transmission of thoughts and emotions, it is important to be able to receive and express affection for another person; (3) mutual acceptance and validation; (4) constructive conflict resolution regard the relationship [13].

Smooth communication is a key for efficient and effective communication among employees. Effectiveness of communication significantly influence: employee relations, motivation and autonomy, flexibility in communication, trust 
between employees and the culture of communication among employees.

\subsection{Changes in the Organization}

An important part of internal communication represents an effective and efficient communication with employees during the introduction of changes and after a change in the organization, since this depends on the successful implementation of the planned changes.

Communication should be two-way, among employees and between management and employees. Even employees are those whose proposals are generated on the basis of their experience with the nature of the work and they are changing the organization [10]. Communication in an organization is a tree way process, as it runs from the top down, from the bottom up and between the various functions.

The unit cell of performance of the organization is individual in relationship with others that contributes the achievement of a vision and goals of the organization. In critical moments needs to be a personal contact between management and employees. It is important that the communication in any situation cannot be waived. Effective communication is a good tool to obtain information about human behavior and effective implementation of change within an organization which leads us internal communication.

\section{Comparison of KM Processes with the Processes of Quality Assurance in HEIs}

KM processes enables HEIs to constantly check and improve quality assurance. In Table 1 we show the parallel implementation of $\mathrm{KM}$ processes and quality assurance processes in HEIs.

Evaluation and self-evaluation are the most common methods to determine quality in the HEIs and at the same time they represent the initial phase of $\mathrm{KM}$ process, namely knowledge identification or capture [26].

Self-evaluation is a comprehensive process of collecting and analyzing information. The aim of an evaluation is to determine the current state of the organization while planning for the future.

Self-evaluation is a process of assessment of the functioning of higher education institutions, carried out by the organization itself and its employees. Selfevaluation includes: evaluation of teaching, which crosses the students and other relevant stakeholders from the environmental evaluation of all activities, evaluating the sufficiency and diversification of sources of national and international environmental and financial performance, documentation of development of an organization in connection with the development of relevant environmental documentation, deficiencies and errors analysis of the achievements and quality assessment of all activities of the organization and making recommendations for improvements.

Table 1: Comparison of KM processes with the processes of quality assurance in HEIs

\begin{tabular}{|c|c|}
\hline KM processes & Quality assurance processes \\
\hline $\begin{array}{c}\text { Knowledge } \\
\text { identification/capture }\end{array}$ & $\begin{array}{l}\text { Evaluation, self-evaluation }[15] \text {, } \\
\text { accreditation, regular annual interviews, } \\
\text { opinion questionnaires, occasional } \\
\text { interviews with the head. }\end{array}$ \\
\hline Knowledge creation & $\begin{array}{l}\text { Education and training, conferences, } \\
\text { seminars, workshops, round tables, } \\
\text { mobility. }\end{array}$ \\
\hline $\begin{array}{l}\text { Knowledge } \\
\text { transfer/sharing }\end{array}$ & $\begin{array}{l}\text { Weekly meetings with support services, } \\
\text { conferences, academic assemblies, chairs, } \\
\text { centres, roundtables, conferences, forums, } \\
\text { e-Moodle, R\&D projects, organized } \\
\text { meetings with stakeholders from the } \\
\text { environment, alumni. }\end{array}$ \\
\hline $\begin{array}{l}\text { Knowledge } \\
\text { application/use }\end{array}$ & $\begin{array}{l}\text { Working in teams or tandems and } \\
\text { working in departments. }\end{array}$ \\
\hline Knowledge storage & $\begin{array}{l}\text { Reports (self-evaluation report, research } \\
\text { and development projects report, the } \\
\text { annual report), professional and scientific } \\
\text { papers, monographs, higher education } \\
\text { ICT-technology system and website. }\end{array}$ \\
\hline
\end{tabular}

Self-evaluation provides the organization with information that is both positive and negative. Successful self-evaluations may threaten the exposure of employee weaknesses, conflicts. An important factor to the success of self-evaluation is the general climate within the organization that allows employees their right to success and failure. An organization can use the results of self-evaluation to improve quality and at the same time offer assistance to those employees who need it with their work. All participants in a self-evaluation have to know that the aim is to assess and assure quality in the organization. It must not become an instrument for resolving conflicts and tensions within the organization.

The other methods used are also accreditation, regular annual interviews, opinion questionnaires, occasional interviews with the head etc. Accreditation is a process in which certification of competency, authority, or credibility is presented. In order to effectively ensure the success of career plan is important a long interview where the manager and employee can review the results in the previous period, plan objectives and activities to enhance the performance in the next period, and identify activities that are associated with the work, professional and personal development of the employees. Baker identifies four types of interviews: assessment interview, the interview that is based on individual responsibility and empowering, coaching interviews and counseling interviews [1]. The 
interview is generally planned and carried out in the same time periods (annual, semi-annual, monthly ...), which usually takes place once a year, if it is a longer form of conversation that is primarily intended for development in the future. The interview between the manager and the employees is a confidential nature. The interview can be a group or individual type. With an annual interview the manager has: to download the objectives of the organization to an employee, to clear expectations on performance, to provide feedback and help to an employee to advise an employee to find his way to the expected results and identify his strengths and weaknesses, to determine a development plan to improve performance. Mumel says that the purpose of conducting annual interviews is to motivate employees to think about their work and plans and prepare their own suggestions on how to improve things, it is also the purpose of achieving that associates can reflect on its role in organization and to achieve to get an overview of the priorities of his duties, what is expected from them in the next year (period), to achieve in order to be co-workers even more independent, responsible and initiatory, to carry out their duties and to consider good sites of employee and where he still has reserves that are worth to benefit from [14].

Knowledge creation happens during education and training, conferences, seminars workshops, round tables and through mobility experience. Knowledge transfer is most effective through networking, meetings, forums, projects etc. While knowledge application is possible when working in teams and tandems, knowledge storage on the other hand is connected to reports and higher education outputs such as annual reports, professional and scientific papers, monographs etc.

With the aim of providing quality, HEIs use Quality manual which defines quality system, procedures and instruments for quality assurance, integration and networking of all stakeholders involved in the processes of the organizations' operations. In the case of Slovenia areas that are subject to quality assessment of HEIs are: integration and cooperation with the environment, the operation of the HEIs (justification for the need for educational programs and implementation of training), staff, students, material conditions (facilities, equipment, library and information activity and funding), quality assurance, innovation and development orientation [12]. Continuous and systematic monitoring of these areas is a precondition for identifying outstanding, stronger or weaker points and is the basis for planning improvements.

\section{Conclusion}

In the presence of knowledge economy implicit and explicit knowledge have become the main resources for any organization and HEIs are no exceptions.

Smith and McKeen [17] believe that the manager's task is to know which departments need to create additional knowledge. In the process of $\mathrm{KM}$ the manager must operate to achieve an effective use of new and prior knowledge to ensure a competitive advantage and working performance. With good planning strategy, knowledge acquisition, monitoring and knowledge transfer between employees, HEI can provide a good exploitation of new knowledge. In addition, parallel monitoring of $\mathrm{KM}$ processes as well as quality assurance processes also affects the competitive advantage of the HEIs. Very important aspect is an internal communication as a tool to assure quality of an organization (see Figure 1).

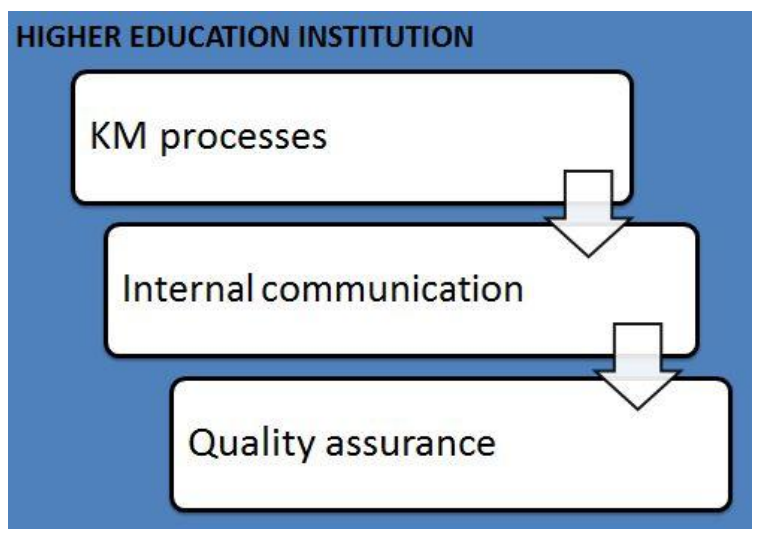

Figure 1. Achieving quality assurance thru KM processes and internal communication

We can conclude that efficient and effective KM cannot be achieved without extensive behavioral, cultural and organizational change that includes at least some aspects of quality assurance.

The system of internal communication is successful if the objectives are being transmitted over the management of the all organization levels of the organization and that employees are aware of what their role is and what behavior should be developed that changes can be made.

\section{References}

[1] A. Baker, Improve Your Communication Skills. Revised Second Edition. Kogan Page, London, Philadelphia. 2010.

[2] I. Becerra - Fernandez, A. Gonzales and R. Sabherwal, Knowledge management Chllenges, Solutions and Technologies. Pearson Education, Inc, New Jersey, NJ, 2004.

[3] B. Bergeron, Essentials of knowledge management. Hoboken, John Wiley \& Sons, New Jersey, NJ, 2003.

[4] C. Collison, and G. Parcell, Učimo se leteti: Priročnik za upravljanje znanja, GV Založba, Ljubljana, 2002. 
[5] M. Černelič, "Procesi pridobivanja, uporabe, prenosa in hranjenja znanja v podjetju". In S. Možina and J. Kovač (ed.), Menedžment znanja - znanje kot temelj razvoja na poti k ис̌ес̌emu se podjetju (pp. 71-93). Založba Pivec, Maribor, 2006.

[6] V. Dermol, Uvod v sisteme managementa znanj, http.//novis.mfdps.si/student/gradiva/?idue=28, 2011. (Access date 8 December 2014)

[7] V. Dimovski, S. Penger, M. Škerlavaj, and J. Žnidaršič, Učeča se organizacija: ustvarite podjetje znanja, GV Založba, Ljubljana, 2005.

[8] M. Ferjan, Management izobraževalnih procesov. Moderna organizacija, Kranj, 2005.

[9] A. Koren, Ravnatelj med osamo in sodelovanjem. Šola za ravnatelje, Ljubljana, 1999.

[10] S. Košir, Letni razgovor kot orodje za spremembo in razvoj človeških virov v organizaciji. Sodobni izzivi managementa človeških virov. MFDPŠ, Celje, 2013.

[11] J. Liebowitz, What They Didn' Tell You About Knowledge Management. The Scarecrow Press, Inc. Oxford, 2006.

[12] Merila za akreditacijo in zunanjo evalvacijo visokošolskih zavodov in študijskih programov. Official Gazette of the Republic of Slovenia, no. 95/2010.

[13] S. Možina, M, Tavčar, N. Zupan, A. N. Kneževič, Poslovno komuniciranje. Založba Obzorja, Maribor, 2004.

[14] D. Mumel , Komuniciranje v poslovnem okolju. De Vesta, Maribor. 2008.

[15] K. Musek Lešnik, and K. Bergant, Samoevalvacija v vzgojno-izobraževalnih ustanovah. Inštitut za psihologijo osebnosti, Ljubljana, 2001.

[16] I. Nonaka and H. Takeuchi, The knowledge-creating company : how Japanese companies create the dynamics of innovation, Oxford University Press, New York, Oxford (UK), 1995.

[17] H.A Smith and J.D. McKeen, Developments in Practice XII: Knowledge-Enabling Business Processes. Communications of the Association for Information Systems, http://aisel.aisnet.org/cais/vol13/iss1/4/, 2004. (Access date 8 December 2014)

[18] L. Smith, P. Mounter, Effective Internal Communication. Second Edition. Chartered Institute of Public Relations, Philadelphia, 2008.

[19] D. Štrajn, Evalvacija, Pedagoški institute, Ljubljana, 2000.

[20] N. Turnšek, "Evalvacija za dobro prakso", IB revija, XXXI, 2007, pp. 11-20.

[21] S. Wang, R. A. Noe, \& Z. M. Wang, An exploratory examination of the determinants of knowledge sharing.
Society for Industrial Organizational Psychology, Dallas, 2005.

[22] K.M. Wiig, Knowledge management foundations. Schema press, Arlington, 1997. 